\title{
ÁREAS VERDES: BEM-ESTAR E SEGURANÇA NOS ESPAÇOS PÚBLICOS NA ÁREA CENTRAL DA CIDADE DO RIO DE JANEIRO
}

\author{
Jorge Crichyno ${ }^{1}$
}

\begin{abstract}
RESUMO
Este trabalho tem por objetivo discutir o problema das áreas verdes nos espaços públicos, especialmente, aqueles que integram a área central da Cidade do Rio de Janeiro, compreendendo 24 espaços públicos, sendo entrevistados homens e mulheres de 15 a 60 anos escolhidos para pesquisar, buscando compreender qual a importância da percepção sobre as áreas verdes nas sensações de bem-estar e da segurança dos frequentadores desses espaços públicos. A pesquisa de campo, realizada em abril e maio de 2014, por meio da qual foram aplicados 104 questionários aos usuários em geral e realizadas 5 entrevistas com agentes dos espaços públicos existentes em 10 bairros da AP1 (Área de Planejamento 1, conforme site da Prefeitura do município do RJ) correspondendo à área central da Cidade do Rio de Janeiro, com exceção do bairro de Paquetá (em razão da falta de continuidade física). A pesquisa quali-quantitativa procurou investigar por intermédio da formulação das hipóteses e concluiu que, segundo os dados pesquisados, as áreas verdes constituem elementos que proporcionam sensações de bem-estar nos espaços públicos. Este trabalho buscou compreender qual a importância da percepção das áreas verdes nas sensações de bem-estar e da segurança dos frequentadores desses espaços públicos.
\end{abstract}

PALAVRAS-CHAVE: Áreas Verdes. Bem-Estar e Segurança. Cidade do Rio de Janeiro.

\section{GREEN AREAS: HEALTH AND SAFETY IN PUBLIC SPACES IN CENTRAL AREA OF RIO DE JANEIRO CITY}

\begin{abstract}
This work aims to discuss the problem of green areas in public areas, especially those that make up the central area of the City of Rio de Janeiro, comprising 24 public spaces, being interviewed men and women 15-60 years chosen to research, seeking understand how important the perception of the green areas in wellness sensations and safety of patrons of these public spaces. The field survey, conducted in April and May 2014, by which 104 questionnaires were applied to general users and conducted five interviews with agents of existing public spaces in 10 districts of the AP1 (Planning Area 1, as the City Hall site RJ municipality) corresponding to the central area of the City of Rio de Janeiro, with the exception of Paqueta neighborhood (because of lack of physical continuity). The
\end{abstract}

1 Mestre Doutorando Professor do Depto. Urbanismo da UFF, jorgecrichyno@hotmail.com. 


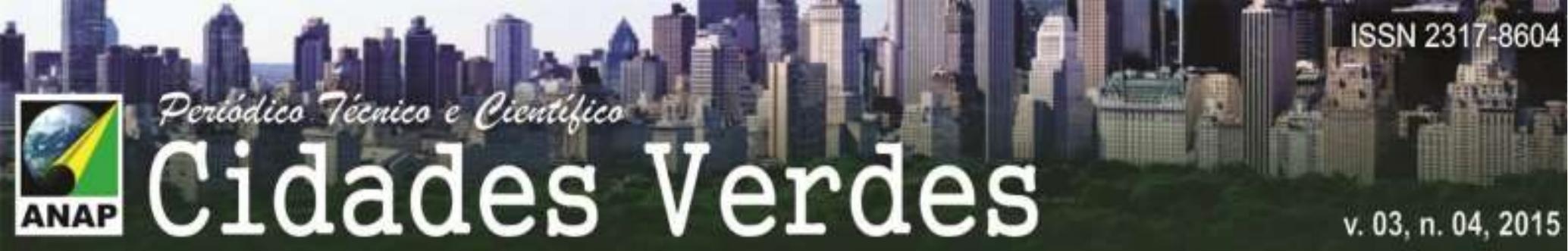

qualitative and quantitative research sought to investigate through the formulation of hypotheses and concluded that, according to data surveyed, the green areas are elements that provide wellness feelings in public spaces. This study aimed to understand how important the perception of green areas in wellness sensations and safety of patrons of these public spaces.

KEYWORDS: Green areas. Wellness and Safety. City of Rio de Janeiro.

\section{ZONAS VERDES: SALUD Y SEGURIDAD EN ESPACIOS PÚBLICOS EN LA ZONA CENTRAL DE LA CIUDAD DE RIO DE JANEIRO}

\section{RESUMEN}

Este trabajo tiene como objetivo discutir el problema de las zonas verdes en las zonas comunes, sobre todo los que componen la zona central de la ciudad de Río de Janeiro, que comprende 24 espacios públicos, siendo los hombres y mujeres de 15 a 60 años entrevistados seleccionados para la investigación, la búsqueda de comprender la importancia de la percepción de las áreas verdes en las sensaciones y la seguridad de los clientes de estos espacios públicos de bienestar. El estudio de campo, realizado en abril y mayo de 2014, por el cual 104 cuestionarios se aplicaron a los usuarios en general y realizaron cinco entrevistas con agentes de los espacios públicos existentes en 10 distritos de la (Área de Planificación AP1 1, como el sitio Ayuntamiento municipio RJ) que corresponde a la zona central de la ciudad de Río de Janeiro, con la excepción del barrio de Paquetá (a causa de la falta de continuidad física). La investigación cualitativa y cuantitativa trató de investigar a través de la formulación de hipótesis y la conclusión de que, según datos de la encuesta, las zonas verdes son elementos que proporcionan sensaciones de bienestar en los espacios públicos. Este estudio tuvo como objetivo comprender la importancia de la percepción de las zonas verdes en las sensaciones y la seguridad de los clientes de estos espacios públicos de bienestar.

PALABRAS CLAVE: Areas verdes. Bienestar y Seguridad. Ciudad de Río de Janeiro.

\section{INTRODUÇÃO}

A relevância do tema é fundamentada considerando-se que o espaço público nas cidades brasileiras vem assumindo inúmeras formas e expressões, compreendendo desde uma calçada até a paisagem urbana vista em perspectiva, abrangendo também formas mais conhecidas tais como as ruas, as praças, os parques e as áreas verdes inseridos na malha urbana. A palavra "público" indica que 
os locais que concretizam esse espaço são abertos e livres, acessíveis sem exceção, a todas as pessoas.

No Brasil, a redução do apreço e o esvaziamento das áreas verdes nos espaços públicos urbanos não são acidentais. Além das razões demográficas e econômicas, que estariam por traz desta neutralização dos espaços públicos das cidades, como diz Sennett (1994), existe outra razão que leva as pessoas a tolerar este empobrecimento de suas experiências cotidianas na cidade. Esta transformação da cena urbana "em uma realidade pasteurizada, formada de espaços neutros e suavizados que pretendem remover todos os riscos implícitos nos contatos sociais indesejados, reflete um medo de exposição a uma realidade social ameaçadora" (LIMA; PELLEGRINO, 1996, p. 197).

A questão central do objeto de pesquisa tem como argumento que as áreas verdes não significam simplesmente espaços não construídos. Esses são denominados os espaços livres, e não necessariamente verdes. Também não são apenas áreas de solo não impermeabilizado, mas sim espaços urbanos não construídos e devidamente protegidos, onde domina o elemento vegetal, notadamente as árvores, de forma a fornecer benefícios de bem-estar e segurança para os frequentadores dos espaços públicos da cidade.

Paulo César da Costa Gomes (2002) ressalta que uma concepção do espaço público, que além da ideia de liberdade e igualdade, tenha como base a separação do privado ou a delimitação jurídica, ou mesmo a garantia do acesso livre, "é insuficiente para definir o caráter fundamentalmente político de seu significado". Para Gomes, "os atributos de um espaço público são aqueles que têm relação com a vida pública [...] E, para que esse 'lugar' opere uma atividade pública, é necessário que se estabeleça, em primeiro lugar, uma copresença de indivíduos" (GOMES, 2002, p. 160).

Esse autor defende o espaço público como o lugar da sociabilidade da vida pública em que se exercita a arte da convivência. Para ele, "o lugar físico orienta as práticas, guia os comportamentos, e estes, por sua vez, reafirmam o estatuto público deste espaço" (ibid, p. 163). O espaço público, portanto, deve ser visto como um 
conjunto indissociável das formas assumidas pelas práticas sociais e percepção de bem-estar.

As inquietudes causadas pela transformação dos espaços públicos, especialmente daqueles de seus aspectos relacionados aos modos de vida pública, na sociedade contemporânea provocaram, a partir da segunda metade da década de 1980, o surgimento de numerosos estudos e debates a respeito do chamado "espaço público", principalmente nos Estados Unidos. Essas discussões foram impulsionadas em parte pela reação contra a homogeneização dos espaços públicos nas áreas centrais das cidades.

Isso se deu também pela popularidade atingida por alguns livros e publicações que assumiam posturas críticas às formas da vida e dos espaços públicos urbanos, tais como $A$ morte e a vida nas grandes cidades americanas (lançado em 1961), de autoria de Jane Jacobs, e a "tirania da domesticidade sobre a vida pública", como O declínio do homem público (original em inglês publicado em 1974) de autoria de Richard Sennett.

Dentro da malha urbana destacam-se os espaços públicos cujos atributos têm uma relação direta com a vida pública. A oferta e a qualidade das áreas verdes nos espaços livres públicos deveria ser a primeira condição para o projeto urbano. Os espaços públicos que deveriam ser "lugar de todos", tornaram-se em muitos casos, "terra de ninguém" e, muitas vezes, vem sendo apropriado em múltiplos usos. Assim, "a cidade informal passou a emergir bem no meio da cidade moderna e formal" (VAZ; SILVEIRA, 1998, p. 9).

Considerando-se o problema das Áreas Verdes como elemento de segurança e bem-estar dos frequentadores nos Espaços Públicos, propõe-se como especulação teórica investigar e testar a formulação das seguintes hipóteses contextualizadas no Marco Teórico: $\mathrm{H} 1$ : As áreas verdes constituem elementos que proporcionam sensações de bem-estar nos espaços públicos. H2: As áreas verdes constituem elementos que proporcionam sensações de segurança nos espaços públicos. Em termos de operacionalização das questões propostas para testar as hipóteses, destacam-se as seguintes indagações: 1. Qual a importância da percepção sobre as áreas verdes nas sensações de bem-estar dos frequentadores 
nos espaços públicos? 2. Qual a importância da percepção sobre as áreas verdes nas sensações de segurança dos frequentadores nos espaços públicos?

\section{OBJETIVO}

Este trabalho tem por objetivo discutir o problema das áreas verdes nos espaços públicos, especialmente, aqueles que integram a área central da Cidade do Rio de Janeiro, escolhidos para pesquisar, buscando compreender qual a importância da percepção sobre as áreas verdes nas sensações de bem-estar e da segurança dos frequentadores desses espaços públicos.

\section{METODOLOGIA}

A pesquisa de campo, realizada em abril e maio de 2014, na qual foram selecionados 24 espaços públicos, sendo entrevistados homens e mulheres de 15 a 60 anos, aplicados 104 questionários e realizadas 5 entrevistas com os agentes de espaços públicos existentes em 10 bairros da AP1 (Área de Planejamento 1, conforme site da Prefeitura do município do RJ) correspondendo à área central da Cidade do Rio de Janeiro, com exceção dos bairros de Paquetá (em razão da falta de continuidade física), Caju, Estácio e Mangueira (em razão de não haver espaços públicos cadastrados na PMRJ), a saber: Saúde, Gamboa, Santo Cristo, Centro, Catumbi, Rio Comprido, Cidade Nova, São Cristóvão, Benfica, Santa Teresa.

Foi adotada a divisão de bairros baseada na demarcação do Mapa 1 que mostra o cadastro de logradouros públicos e praças (Fonte: Instituto Pereira Passos IPP. Também foi obtida no site do Google Maps a visualização do mapa que mostra as divisões internas dos bairros que compõem a AP1. Na definição da amostragem para aplicação dos questionários em campo, foi definida previamente a quantidade de entrevistas nos espaços públicos a serem pesquisados, totalizando 104 o número de frequentadores. 


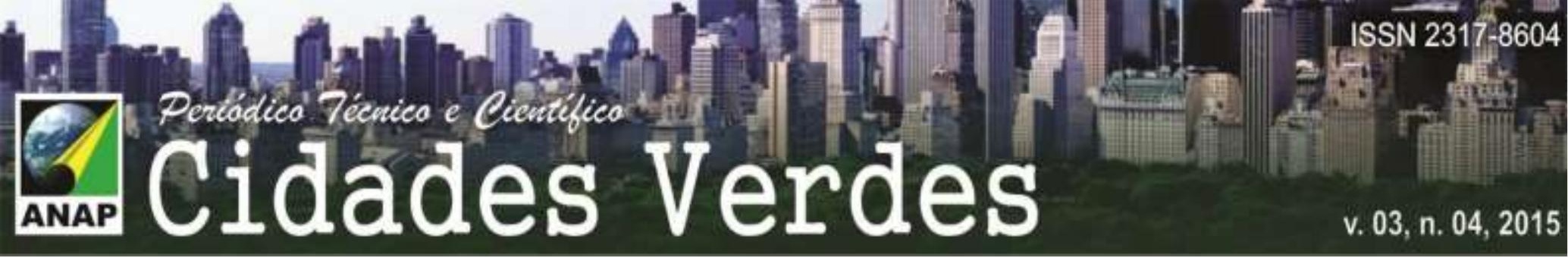

O bem-estar e a segurança nas áreas verdes foram estudados no contexto dos espaços públicos da AP1/RJ, nas quais foram testadas as hipóteses formuladas por meio da aplicação de uma pesquisa de caráter quasi-experimental desenvolvida para este estudo.

Mapa 1 - AP1 com praças e bairros da Cidade do Rio de Janeiro

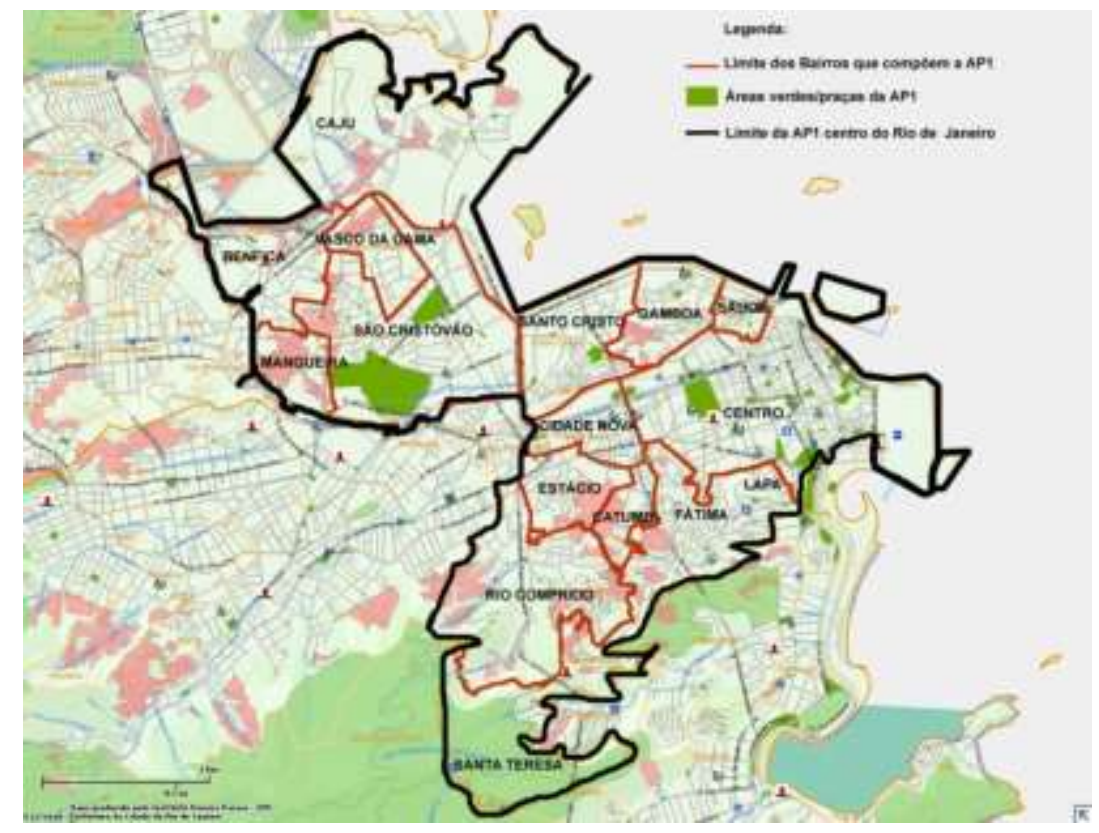

Fonte: Prefeitura Municipal do Rio de Janeiro (IPP) - Mapa Digital. Ano 2013.

Esses espaços públicos correspondem a $46 \%$ do total da amostragem dos espaços públicos na cidade do Rio de Janeiro, sendo que destes, 44\% foram definidos como espaços públicos abertos e 60\% como espaços públicos próximo de edificação abrangendo os bairros mencionados anteriormente e que compõem a AP1/RJ.

Assim, a pesquisa quali-quantitativa foi baseada inicialmente na aplicação de um questionário junto aos respondentes selecionados em campo, abrangendo uma amostra de 104 frequentadores dos espaços públicos dos bairros da AP1. Estes questionários contendo 28 questões, sendo a maioria delas fechadas e algumas abertas (41 variáveis), e na realização de 5 entrevistas. A ênfase dada foi dada na integração dos dados obtidos no estudo das variáveis, frequências e correlações 
referentes à amostra dos 44 frequentadores aos espaços livres públicos longe dos EPEs, que correspondem efetivamente às áreas verdes públicas.

$\mathrm{Na}$ aplicação dos questionários, foram asseguradas condições similares em termos de faixas etárias (15-29, 30-59 e 60+) para homens e mulheres com faixa de renda variando de 3 SM (salário mínimo) a 10 SM. Também foi estabelecido na metodologia de aplicação dos questionários para o universo de frequentadores dos espaços públicos o horário comercial de segunda a sexta-feira no horário de $9 \mathrm{~h}$ as 18h. As perguntas que constam do questionário são em sua maioria formuladas por questões fechadas com algumas questões abertas, totalizando um quantitativo de 28 perguntas para a pesquisa.

A frequência estabelecida não correspondeu aos números de bairros e sim no método de aproximação de proporção (folha de cota), em função dos números de espaços públicos que cada bairro possui, buscando assegurar uma proporção na distribuição e aplicação dos questionários (formulário) e garantir maior qualidade e validade nas respostas dos questionários.

Os dados foram tabulados pela equipe de coordenação e de pesquisadores e processados pelo programa da IBM SPSS Statistics 20, resultando em quadros que mostraram as frequências e correlações entre as 41 variáveis estudadas. No estudo, foram descritas as frequências e porcentagens das variáveis para bem-estar e segurança das áreas verdes em termos das correlações significantes entre elas.

Em complementação, a pesquisa qualitativa teve por objetivo esclarecer alguns dados e identificar os questionamentos que pudessem revelar alguns pontos dos resultados obtidos na pesquisa quantitativa e verificados com relação à percepção dos frequentadores pesquisados em termos das sensações de bem-estar e segurança nas áreas verdes que compõem o universo da amostra.

Para viabilizar uma melhor compreensão das informações obtidas, utilizouse a técnica de entrevista contendo 10 questões abertas, que foram aplicadas a 5 entrevistados para emitirem opiniões sobre o problema apresentado. Nestas entrevistas, foi adotada como critério de escolha a seleção de alguns frequentadores de áreas verdes e representantes da sociedade civil organizada, de caráter sócio institucional, por intermédio de entrevistas gravadas feitas aos seguintes exemplos 
de agentes participativos: Instituição de Gestão Pública Municipal (1), Associação de Moradores (1), Universidade Pública (1), Associação de Classe Profissional (1) e Frequentador de Áreas Verdes Públicas (1).

A partir do estabelecimento da formulação das hipóteses e consequente teste por meio da avaliação da pesquisa em caráter quasi-experimental, pretendeuse buscar a definição das possíveis correlações entre as variáveis "bem-estar" e "segurança", além de mensurar a correlação "frequência em áreas verdes", identificando a provável associação com as demais variáveis supracitadas em relação ao grau de significância.

A integração das análises das pesquisas quantitativa e qualitativa pretendeuse obter a descrição das frequências e porcentagens das variáveis de interesse para a pesquisa, bem como a ocorrência de correlações significantes entre elas apresentando resultados que respondessem às questões formuladas, visando à confirmação ou rejeição das hipóteses contextualizadas e as possíveis conexões explicativas relacionadas ao marco teórico estabelecido sobre o tema.

Como objeto de especulação teórica para a investigação do problema de pesquisa de caráter quali-quantitativa, considerou-se o marco teórico como base para a formulação das hipóteses da pesquisa e as questões relativas ao bem-estar e segurança, que estão diretamente relacionadas a melhor qualidade de vida nas cidades. Nesse contexto, a cidade é pensada dentro de uma dimensão ampla e humana, para além de sua materialidade física, que se corporifica em seus próprios cidadãos e nas relações que ocorrem em seu espaço, buscando fazer com que a cidadania de fato faça parte do cotidiano urbano.

A esfera da vida pública é própria da "vita activa" (ARENDT, 1958), da ação política, entendida em sentido amplo, envolvendo a produção cultural e a construção da cidadania. É na esfera pública que se dão as diferenças e divergências possibilitando os discursos comunicativos.

Daí decorre o acordo político em seu sentido maior, "a noção de interesse público, de bem público, constituído socialmente diante do conflito de interesses" (QUEIROGA, 2007, p. 84). O bem público não deve ser confundido com a noção de 
bem comum, pois o primeiro é resultado da construção dialética da política, e o segundo, se produz enquanto expressão ideológica da classe dominante.

Denomina-se de espaços públicos "os lugares de uso comum do povo, como ruas, praças, parques, imóveis públicos e todos os lugares de apropriação pública, onde se realizam ações da esfera pública, de propriedade pública ou privada. Prescindem de estrutura física, tangível” (CAPANEMA ÁLVARES, 2013, p. 4).

Macedo (1995) define qualificação como a possibilidade de apropriação que o espaço permite ao seu público usuário, a qual permitirá aceitação social e manterá por mais tempo sua identidade morfológica.

\section{RESULTADOS DAS ANÁLISES QUANTITATIVA E QUALITATIVA}

A análise quantitativa foi baseada na descrição das frequências e porcentagens das variáveis de interesse para a pesquisa e ocorrência de correlações significantes entre elas. Para tanto, são apresentados diversos quadros contendo dados estatísticos das frequências nas variáveis em áreas verdes, avaliação de bem-estar e motivo para insegurança, mostrando possíveis correlações e hierarquia de pontuações.

Em relação ao bem-estar nas áreas verdes dos espaços públicos abertos, o Quadro 1 abaixo mostra os percentuais correspondentes aos 44 frequentadores desses espaços, sendo que 27.3 \% classificam um bom nível de seu bem-estar (nota 7.0), enquanto $25 \%$ consideram a avaliação regular e apenas $13.6 \%$ consideram como um nível ótimo (nota 10.0), enquanto $13.6 \%$ dos frequentadores classificam seu bem-estar nesses espaços como insatisfatórios (curva bimodal). Observa-se que a média das pontuações de nota é de 6.3 e a moda é de 7.0. 
Quadro 1: avaliação de bem-estar

avaliação de bem estar

\begin{tabular}{|rr|r|r|r|r|}
\hline & & & & \multicolumn{2}{c|}{$\begin{array}{c}\text { Cumulative } \\
\text { Percent }\end{array}$} \\
\hline Valid & 1.00 & 3 & 6.8 & 6.8 & 6.8 \\
& 2.00 & 2 & 4.5 & 4.5 & 11.4 \\
3.00 & 1 & 2.3 & 2.3 & 13.6 \\
5.00 & 11 & 25.0 & 25.0 & 38.6 \\
6.00 & 3 & 6.8 & 6.8 & 45.5 \\
7.00 & 12 & 27.3 & 27.3 & 72.7 \\
8.00 & 4 & 9.1 & 9.1 & 81.8 \\
9.00 & 2 & 4.5 & 4.5 & 86.4 \\
10.00 & 6 & 13.6 & 13.6 & 100.0 \\
Total & 44 & 100.0 & 100.0 & \\
\hline
\end{tabular}

Fonte: Dados de Pesquisa: amostra de frequentadores de espaços públicos na AP1/RJ. Ano 2014.

Pesquisa divulgada em abril de 2014 informa o que a sociedade já vem percebendo há muito tempo. Pesquisadores da Universidade de Wisconsin, nos Estados Unidos, constataram que pessoas que vivem perto de áreas verdes são mais propensas a ter saúde e bem-estar. E com algumas iniciativas, quem vive no meio urbano também pode trazer um pouco dessa felicidade para perto de si.

Outras pesquisas feitas por cientistas britânicos afirmam que moradores que vivem perto de áreas verdes, os estudos indicam um aumento da sensação de bemestar destas áreas e apontam que estas pessoas apresentam menos sinais de depressão e ansiedade, sugerindo que viver em uma área urbana com espaços verdes tem um impacto positivo no bem-estar mental dos habitantes de diversas cidades britânicas.

Quanto à análise dos dados em relação à problemática da insegurança nas áreas verdes dos espaços públicos abertos, o Quadro 2 mostra os percentuais totais dos 44 frequentadores desses espaços, 45.5\% apontam mais de um dos motivos relacionados para justificarem sua insegurança, enquanto $18.2 \%$ consideram a avaliação da situação do espaço atribuindo fama de perigoso. Outros frequentadores 
(15.9\%) classificam os espaços como lugar deserto/escuro, enquanto $11.4 \%$ consideram o lugar como desconhecido. Em termos de avaliação da sensação de insegurança desses espaços, alguns frequentadores consideram local com restrição de horário (4.5\%) e outros avaliam como local murado ou com aparência de particular $(4.5 \%)$.

Quadro 2: motivo para insegurança

motivo para insegurança

\begin{tabular}{|c|c|c|c|c|c|}
\hline & & Frequency & Percent & Valid Percent & $\begin{array}{l}\text { Cumulative } \\
\text { Percent }\end{array}$ \\
\hline \multirow[t]{7}{*}{ Valid } & lugar deserto/escuro & 7 & 15.9 & 15.9 & 15.9 \\
\hline & lugar desconhecido & 5 & 11.4 & 11.4 & 27.3 \\
\hline & fama de perigoso & 8 & 18.2 & 18.2 & 45.5 \\
\hline & $\begin{array}{l}\text { local com restrição de } \\
\text { horário }\end{array}$ & 2 & 4.5 & 4.5 & 50.0 \\
\hline & $\begin{array}{l}\text { local murado ou com } \\
\text { aparência de particular }\end{array}$ & 2 & 4.5 & 4.5 & 54.5 \\
\hline & mais de um dos motivos & 20 & 45.5 & 45.5 & 100.0 \\
\hline & Total & 44 & 100.0 & 100.0 & \\
\hline
\end{tabular}

Fonte: Dados de Pesquisa: amostra de frequentadores de espaços públicos na AP1/RJ. Ano 2014.

Contemporaneamente, assiste-se a uma alteração marcante na qualidade do espaço público e no significado da noção de público que caracterizou a emergência da vida moderna. Essa alteração apoia-se na atribuição de ameaça a alguns grupos que compõem a população, aliada à descrença e à desconfiança na capacidade de os poderes públicos garantirem a segurança dos cidadãos, o que tem levado a uma progressiva transferência dessa responsabilidade para as empresas privadas de segurança.

O Quadro 3 mostra que os maiores percentuais em relação à faixa etária dos frequentadores de espaços públicos referem-se à variação de idade de 30 a 59 anos (52,3\%), enquanto que a variação de 15 a 29 anos apresenta percentual de $27,3 \%$, superando a faixa de idade de 60 ou mais anos que corresponde a $20,5 \%$. 
Quadro 3: Frequência em áreas verdes por Idade

\begin{tabular}{|c|c|c|c|c|c|}
\hline & & Frequency & Percent & Valid Percent & $\begin{array}{c}\text { Cumulative } \\
\text { Percent }\end{array}$ \\
\hline \multirow{4}{*}{ Valid } & 15 a 29 & 12 & 27,3 & 27,3 & 27,3 \\
\hline & 30 a 59 & 23 & 52,3 & 52,3 & 79,5 \\
\hline & 60 ou mais & 9 & 20,5 & 20,5 & 100,0 \\
\hline & Total & 44 & 100,0 & 100,0 & \\
\hline
\end{tabular}

Fonte: Dados de Pesquisa: amostra de frequentadores de espaços públicos na AP1/RJ. 2014.

Observa-se também, que em contrapartida, quanto menor a nota pontuada na classificação entre os frequentadores de sua segurança nas áreas verdes, mais são os motivos de insegurança. Ainda assim, os dados quantitativos revelam que as pessoas preferem locais de espaços públicos abertos.

Nesse sentido buscou-se realizar um estudo de interpretação das correlações significativas entre frequência em áreas verdes, avaliação de bem-estar e motivo de insegurança como mostra o Quadro 4 (Correlação de Pearson), objetivando verificar a formulação das hipóteses.

Quadro 4: Correlação de Pearson - Frequência em áreas verdes, avaliação de bem-estar e motivo de insegurança

\begin{tabular}{|ll|r|r|r|}
\hline & & $\begin{array}{c}\text { avaliação de } \\
\text { bem estar }\end{array}$ & $\begin{array}{c}\text { motivo para } \\
\text { insegurança }\end{array}$ & $\begin{array}{c}\text { Frequência em } \\
\text { áreas verdes }\end{array}$ \\
\hline avaliação de bem estar & Pearson Correlation & 1 &, 015 &,$- 411^{* *}$ \\
& Sig. (1-tailed) & N & 44 &, 003 \\
& Pearson Correlation &, 015 & 463 & 44 \\
motivo para insegurança & Sig. (1-tailed) &, 463 &,- 014 \\
& $\mathrm{~N}$ & 44 &, 463 \\
& Pearson Correlation &,$- 411^{* *}$ & 44 & 44 \\
Frequência em áreas & Sig. (1-tailed) &, 003 &,- 014 & 1 \\
verdes & $\mathrm{N}$ & 44 &, 463 & 44 \\
\hline
\end{tabular}

${ }^{* *}$. Correlation is significant at the 0.01 level (1-tailed).

r: coeficiente de Pearson; $\mathrm{p}$ : nível de significância 1-caudal; $\mathrm{N}$ : número de casos

Fonte: Dados de Pesquisa: amostra de frequentadores de espaços públicos na AP1/RJ. Ano 2014. 
Na correlação entre frequência em áreas verdes e avaliação de bem-estar, observa-se que a correlação é negativa e que o do nível de significância é muito baixo e mostra que os resultados são estatisticamente muito significativos, ou seja, pode-se afirmar com $99 \%$ de certeza que houve correlação. Tem-se um coeficiente de determinação, indicando que $16,90 \%$ da variância frequência em áreas verdes é "explicada" pela variância de avaliação de bem-estar. Portanto, a frequência em áreas verdes é moderada e explica $16,90 \%$ da sensação da avaliação de bem-estar.

Observa-se que quanto maior a nota que os frequentadores classificam seu bem-estar nas áreas verdes maior é o bem-estar proporcionado por elas, caracterizando uma relação de causalidade: quanto mais frequentação das áreas verdes, maior é sensação de bem-estar. E em relação a variável frequência das pessoas no destino às áreas verdes, quanto mais vezes se frequenta as áreas verdes, consequentemente maior é a nota de bem-estar.

$\mathrm{Na}$ correlação entre frequência em áreas verdes e motivos para insegurança, apresenta-se um coeficiente negativo, mostrando que as variáveis variam em sentido inverso (valor baixo de uma variável está associado ao valor alto de outra variável). Portanto, tem-se uma correlação negativa com grau de significância moderado indicando que quanto maior for a frequência em áreas verdes, haverá menos motivo para sensação de insegurança. $O$ valor do coeficiente de determinação indicando que o percentual da proporção de variância de uma variável "explicada" pela variância da outra nesse caso é de apenas 0,02\%.

Com base na descrição das frequências e porcentagens observadas nas variáveis estudadas e suas correlações significativas (dados da pesquisa quantitativa), foi possível elaborar alguns questionamentos sobre o tema pesquisado.

A pesquisa qualitativa buscou esclarecer alguns dados e identificar questionamentos, capazes de revelar alguns pontos dos resultados verificados na pesquisa quantitativa com relação à percepção dos frequentadores pesquisados em termos das sensações de bem-estar e segurança nas áreas verdes, o que possibilitou viabilizar uma melhor compreensão das informações obtidas com base nos dados da pesquisa. 
Utilizou-se a técnica de entrevistas contendo 10 questões abertas e estas foram aplicadas a 5 entrevistados com o objetivo de expressarem opiniões sobre o problema apresentado. Nestas entrevistas, foi adotado como critério a escolha de representantes da sociedade civil organizada, de caráter sócio institucional, por intermédio de entrevistas gravadas feitas aos seguintes agentes participativos: Instituição de Gestão Pública Municipal, Associação de Moradores, Universidade Pública, Associação de Classe Profissional e Frequentador de Áreas Verdes Públicas.

Ao analisar estas informações é possível verificar que as áreas verdes assumem um papel muito importante no espaço urbano tanto na qualidade ambiental como também na qualidade de vida da população que necessita desse espaço público, seja para passear, praticar esportes etc. Com isso, muitas das áreas que poderiam estar assumindo essas finalidades estão abandonadas sem sua efetivação.

As hipóteses foram testadas por meio de quasi-experimento que buscou definir as relações entre as variáveis "bem-estar" e "segurança", demonstrando que a frequência responsável às áreas verdes urbanas como praças, parques, refúgios e jardins, é uma oportunidade para o exercício de convivência solidária entre pessoas e natureza, para o estreitamento dos vínculos familiares e estabelecimento de novas relações de amizades.

Nesse sentido, se configura a possível resposta de caráter para o problema da pesquisa que confirma parte da hipótese no que se refere ao bem-estar, uma vez que as áreas verdes constituem, verdadeiramente, como elementos que proporcionam sensações de bem-estar. Já, em relação à segurança a formulação não é verdadeira uma vez que o abandono das áreas verdes, transformando-as em locais de deposição de lixo e concentração de violência, também denota a fraqueza das instituições e a falta de educação, o despreparo e até o desamparo de uma sociedade, portanto, as áreas verdes não constituem elementos de segurança nos espaços públicos estudados. 


\section{CONCLUSÃO}

Este trabalho teve por objetivo discutir o problema das áreas verdes nos espaços públicos, especialmente, aqueles que integram a área central da Cidade do Rio de Janeiro, escolhidos para a pesquisa, buscando compreender qual a importância da percepção das áreas verdes nas sensações de bem-estar e da segurança dos frequentadores desses espaços públicos.

Considerou-se nesse estudo, que são muitas as razões para o abandono da vida pública e a mudança do conteúdo e do significado da expressão "bem comum" (CALDEIRA, 2000), pois são referentes a um tipo de visão inerente ao desenvolvimento da sociabilidade moderna, nas quais vêm se manifestando nas metrópoles brasileiras, uma indiferença e um afastamento de questões substanciais da vida cívica e política, expressando o pouco valor e reconhecimento atribuídos a algumas demandas sociais da população.

Por um lado, verifica-se que a precariedade das áreas verdes na maior parte das cidades brasileiras e a crescente dificuldade de acesso por parte de grande parcela da população, explicam em parte, a falta de conservação dessas áreas nos diversos espaços públicos urbanos. Por outro lado, a questão também é desafiadora para aqueles que se propõem a estudar a vida metropolitana com relação à segurança das áreas verdes e suas relações entre forma urbana, política e vida cotidiana, implicando um esforço significativo e absolutamente necessário do poder público no sentido de solucionar a questão da segurança da população e também de outros direitos sociais.

A pesquisa quali-quantitativa investigou por intermédio da formulação das hipóteses e concluiu que, segundo os dados pesquisados, as áreas verdes constituem elementos que proporcionam sensações de bem-estar nos espaços públicos. Entretanto, outros resultados obtidos sobre a avaliação das correlações significantes entre as variáveis estudadas, demonstraram que as áreas verdes não constituem elementos que proporcionam as sensações de segurança nos espaços públicos estudados. 


\section{REFERÊNCIAS BIBLIOGRÁFICAS}

ALTMAN, I. e ZUBE, E. H. (orgs.). Public Places and Spaces. New York: Plenum, 1989.

ARENDT, H. A Condição Humana. Trad. Roberto Raposo, $5^{\mathrm{a}}$ ed. Rio de Janeiro: Forense Universitária, 1991.

CALDEIRA, T. P. do Rio. Cidade de Muros: crime, segregação e cidadania em São Paulo. São Paulo, Editora 34/Edusp, 2000.

CAPANEMA ÁLVARES, L. Espaços Livres Públicos: uma análise multidimensional de apropriações e conflitos. Anais do XIII Simpósio de Geografia Urbana. Rio de Janeiro: UERJ, 2013, 19 p.

CUNHA, R. D. A. Os usos, funções e tratamento de áreas verdes de Florianópolis. 2002. Tese (Doutorado) UFFC, Florianópolis, 2002.

GOMES, P. C. A Condição Urbana: ensaios de ecopolítica da cidade. Rio de Janeiro: Bertam, Brasil, 2002.

LIMA, C. P. C. S. e PELLEGRINO, P. R. M. A procura de novos Paradigmas para os Espaços Livres Urbanos. São Paulo. Anais do $2^{\circ}$ ENEPEA, FAUUSP, 1996, pp. 197-204.

LIARDENT, L. R. A. Zonas verdes y espaços livres en la ciudad. Madrid: Closas. Orcoyen, 1982.

LOBODA, C. R. e DE ANGELIS, B. L. D. Áreas Verdes Públicas Urbanas: conceitos, usos e funções. In: Revista Ambiência. Paraná, v. 1, n. 1, jan/jul 2005, p. 125-139.

MACEDO, S. S. Espaços Livres. Revista Paisagem e Ambiente: Ensaios, São Paulo, n. 7, p. 15-56, 1995.

MORO, D. Á. A. As áreas verdes e seu papel na ecologia urbana e no clima urbano. Separata da Revista UNIMAR, Maringá/PR, v.1 p. 15-20, 1976.

QUEIROGA, E. F. Por uma Paisagem Urbana mais bela. Rio de Janeiro. Anais do $1^{\circ}$ ENEPEA, UFRJ/PROURB, 1994, pp. 156-168.

SENNETT, R. The Fall of Public Man. New York: W. W. Norton, 1994 [1974].

TARNOWSKI, L. C. \& MOURA, R. Preservação do meio ambiente e a arborização urbana. In: Encontro nacional de estudos sobre o meio ambiente, 3, Londrina, 1991. Anais. pp. 530-541.

VAZ, L. F. e SILVEIRA, C. B. Transformações e Permanências na área central do Rio de Janeiro. Revista Arquitetura. IAB/RJ, Rio de Janeiro, junho, 1998, ano 29, n. 81. 